\title{
Side Effects Associated with Liraglutide Treatment for Obesity as Well as Diabetes
}

\author{
Young-Gyun Seo* \\ Department of Family Medicine, Hallym University Sacred Heart Hospital, Anyang, Korea
}

Liraglutide is a glucagon-like peptide-1 receptor agonist used as a treatment for type 2 diabetes mellitus, which has been expanded for use at a higher dose in weight control. Therefore, it is necessary to consider adverse reactions of the drug at high doses as well as at lower doses after the indication has been expanded. Body mass index criteria for patients prescribed the drug in the real world tend to be applied less rigorously, which may increase the number of adverse reactions due to over-prescription. Liraglutide treatment was found effective and safe in some studies, while others have warned about its risks. Therefore, this review summarizes the current data available on side effects associated with liraglutide.

Key words: Liraglutide, Glucagon-like peptide-1 receptor, Drug side effect, Adverse drug reaction, Adverse drug event, Diabetes mellitus, Obesity

\author{
Received June 4, 2020 \\ Reviewed June 25, 2020 \\ Accepted August 2, 2020 \\ ${ }^{*}$ Corresponding author \\ Young-Gyun Seo \\ (iD) \\ https://orcid.org/0000-0001-8294-1741 \\ Department of Family Medicine, \\ Hallym University Sacred Heart Hospital, \\ 22 Gwanpyeong-ro 170beon-gil, \\ Dongan-gu, Anyang 14068, Korea \\ Tel: +82-31-380-3805 \\ Fax: +82-31-380-1782 \\ E-mail:yg035@daum.net
}

\section{INTRODUCTION}

Liraglutide, a glucagon-like peptide-1 (GLP-1) receptor agonist, is primarily used to treat type 2 diabetes mellitus (T2DM), but it has also been used to control weight. ${ }^{1}$ While a dose of $1.8 \mathrm{mg}$ is usually administered to treat T2DM, a higher dose of $3.0 \mathrm{mg}$ is prescribed for weight control. Hence, studying adverse reactions of the high dose as well as those of a lower dose of liraglutide is necessary to develop strategies for rational prescription.

A previous study reported that liraglutide had a greater weight loss effect at 52 weeks compared to other weight control drugs, but it also had more drug discontinuations due to adverse reactions among overweight or obese adults. ${ }^{2}$ However, according to another study, liraglutide treatment is effective and safe for weight loss in obese individuals without diabetes. ${ }^{3}$
Unlike the subjects' high body mass index criteria, which were applied in clinical trials related to liraglutide, the body mass index criteria for patients prescribed the drug in the real world tend to be applied less rigorously, which may increase the number of adverse reactions due to over-prescription. Many clinical trials have been carried out that studied liraglutide followed by subsequent metaanalyses of their data. This review draws on those data and summarizes the latest information on side effects associated with liraglutide.

\section{ACUTE PANCREATITIS}

Side effects related to liraglutide use are summarized in Table 1. In patients with T2DM, treatment with incretin-based therapies (GLP-1 receptor agonists and dipeptidyl peptidase 4 [DPP-4] inhibitors) was associated with increased odds of hospitalization due

Copyright (C) 2021 Korean Society for the Study of Obesity

(a) This is an Open Access article distributed under the terms of the Creative Commons Attribution Non-Commercial License (https://creativecommons.org/licenses/by-nc/4.o/) which permits unrestricted non-commercial use, distribution, and reproduction in any medium, provided the original work is properly cited. 
Table 1. Side effects summary

\begin{tabular}{|c|c|c|c|}
\hline Variable & Liraglutide dose & Side effect & Other consideration \\
\hline Serum lipase and amylase level & 1.8 and $3.0 \mathrm{mg}$ & Increase ${ }^{4,5}$ & - \\
\hline Acute pancreatitis & $1.2-3.0 \mathrm{mg}$ & The absolute risk is numerically higher. ${ }^{5,6}$ & - \\
\hline Liver disease & $0.9-1.8 \mathrm{mg}$ & $\begin{array}{l}\text { Improve liver histology and reduce } \\
\text { aminotransferase levels. }{ }^{9,10}\end{array}$ & $\begin{array}{l}\text { Elevation of liver enzymes and development of cholestasis and hepatitis have } \\
\text { been reported during post-approval use. }{ }^{1} \\
\text { Case reports: elevations of liver enzymes }{ }^{11,12} \text { and development of autoimmune } \\
\text { hepatitis }^{12}\end{array}$ \\
\hline Heart rate & 1.2 and $1.8 \mathrm{mg}$ & Increase $\mathrm{e}^{17,18}$ & \\
\hline
\end{tabular}

to acute pancreatitis (AP), increased risk of $\mathrm{AP}$, and increased levels of serum lipase and amylase. ${ }^{26,27}$ While one study found no consistent trend for risk of pancreatitis with DPP-4 inhibitors, ${ }^{28}$ other meta-analyses observed a positive trend towards increased risk for pancreatitis with DPP-4 inhibitors. ${ }^{29,30}$

With GLP-1 receptor agonists, liraglutide $1.8 \mathrm{mg}$-treated patients with T2DM showed a $28 \%$ increase in serum lipase levels and a 7\% increase in serum amylase levels compared with the placebo group, in the Liraglutide Effect and Action in Diabetes: Evaluation of Cardiovascular Outcome Results (LEADER) trial. ${ }^{4}$ During this trial, $0.4 \%$ of liraglutide-treated and $0.5 \%$ of placebo patients developed AP.

In the Satiety and Clinical Adiposity - Liraglutide Evidence (SCALE) trial, $3.0 \mathrm{mg}$ of liraglutide versus placebo showed a $31 \%$ increase in serum lipase levels and a 7\% increase in serum amylase levels. ${ }^{5}$ In addition, the absolute risk of AP in this evaluation was numerically higher in liraglutide $(0.4 \%, 2.65$ events $/ 1,000$ personyears of observation) versus placebo ( $<0.1 \%, 0.44$ events $/ 1,000$ person-years of observation).

A previous study suggested that there was not enough evidence to support an association between liraglutide (0.1-1.8 $\mathrm{mg}$ ) and AP, when used in the treatment of T2DM. ${ }^{31}$ According to a claimbased study, there was no excess risk of AP associated with liraglutide relative to other antidiabetic drugs. ${ }^{32}$ However, a pooled analysis suggested a tendency to slightly increased risk of pancreatitis with GLP-1 receptor agonists. ${ }^{28}$ In addition, a review suggested that the incidences of reported $\mathrm{AP}$ and chronic pancreatitis were numerically greater with liraglutide $(1.2$ and $1.8 \mathrm{mg})$ than with comparators in patients with T2DM. ${ }^{6}$ GLP-1 receptor agonists are likely to cause subclinical pancreatic inflammation, leading to an elevation in enzyme levels, which may explain the increased lipase and amylase blood levels due to liraglutide. ${ }^{5}$

\section{GALLBLADDER OR BILIARY DISEASE}

In the LEADER trial, the risk of acute gallbladder or biliary disease was higher with liraglutide $(1.8 \mathrm{mg})$ compared to placebo. ${ }^{7}$ A recent updated meta-analysis suggested a significant increase in the risk of cholelithiasis in patients treated with liraglutide $(0.6-3.0 \mathrm{mg}){ }^{8}$ GLP-1 suppresses the secretion of cholecystokinin after a meal in normal subjects and patients with type 1 diabetes mellitus (T1DM). ${ }^{33}$ This suppression attenuates the gallbladder contractility, therefore, offering an explanation for the increased risk of adverse gallbladder events.

\section{LIVER DISEASE}

Individual patient-level data meta-analysis of the Liraglutide Effect and Action in Diabetes program suggested that treatment with $1.8 \mathrm{mg}$ of liraglutide significantly reduced alanine aminotransferase 
in patients with T2DM and abnormal baseline alanine aminotransferase and showed a trend towards improving hepatic steatosis. ${ }^{9}$ Studies suggest that in patients with non-alcoholic steatohepatitis, particularly those with diabetes, GLP-1 receptor agonists (including 0.9 and $1.8 \mathrm{mg}$ of liraglutide) may improve liver histology and reduce aminotransferase levels from baseline. ${ }^{10}$

Animal studies suggest that liraglutide attenuates non-alcoholic fatty liver disease by (1) downregulating the expression of inflammatory signaling mediators in the tumor necrosis factor- $\alpha$ pathway, ${ }^{34}$ (2) upregulating an antioxidant protein (Sestrin2)-mediated nuclear factor-erythroid 2-related factor 2/heme oxygenase-1 pathway, ${ }^{35}$ (3) regulating the local renin-angiotensin system, ${ }^{36}$ and (4) bringing about structural changes in gut microbiota associated with hepatic steatosis. ${ }^{37}$

However, elevations of liver enzymes and development of cholestasis and hepatitis have been reported during post-approval use of liraglutide. ${ }^{1}$ There have been case reports of elevations of liver enzymes $^{11,12}$ and development of autoimmune hepatitis ${ }^{12}$ in patients treated with liraglutide $(1.2 \mathrm{mg})$.

\section{KIDNEY DISEASE}

Liraglutide $(1.2 \mathrm{mg})$ appears to be effective in reducing proteinuria, improving renal function, producing an anti-inflammatory effect, and ameliorating lipid metabolism in patients with T2DM and early-stage nephropathy. ${ }^{13}$ In a Scandinavian cohort study, use of GLP-1 receptor agonists was associated with risk reduction in serious renal events compared with DPP-4 inhibitors. ${ }^{14}$

Liraglutide also enhances lipolysis and reduces lipid synthesis to inhibit renal ectopic lipid deposition in diabetic nephropathy rats by promoting adenosine monophosphate-activated protein kinase phosphorylation. ${ }^{38}$ In addition, GLP-1 receptor agonists are known to have a reno-protective effect by reducing blood sugar, blood pressure, and body weight, but are thought to have additional effects that preserve renal function by an unknown mechanism. ${ }^{39}$

However, dehydration due to nausea, vomiting, and diarrhea, increased serum creatinine, and acute renal failure have been reported during post-approval use of liraglutide. ${ }^{1}$ There have been case reports of elevation of serum creatinine and development of acute kidney injury in patients treated with liraglutide $\left(1.8 \mathrm{mg}^{15}\right.$; dosage not reported $\left.{ }^{16}\right)$. One of these cases was thought to be caused by dehydration due to progressively worsening nausea, vomiting, and diarrhea for several weeks, ${ }^{15}$ and the patient even received hemodialysis treatment.

\section{CANCER}

Cancer-related side effects of liraglutide are summarized in Table 2. A recent study found no reported cases of pancreatic or thyroid cancer within a year in patients with T1DM taking insulin treated with liraglutide $(0.6-1.8 \mathrm{mg})$ or placebo. ${ }^{19}$ Another study observed no increase in cancer with the use of GLP-1 receptor agonists (including $0.9-3.0 \mathrm{mg}$ of liraglutide) in patients with $\mathrm{T} 2 \mathrm{DM} .^{40} \mathrm{In}$ a previous study of patients with T2DM, use of liraglutide $(0.1-1.8 \mathrm{mg})$ increased the risk of cancer by $35 \%$, but was not statistically significant. ${ }^{31}$ However, the cancer risk became statistically significant when only high-quality methodological studies were considered.

Table 2. Cancer-related side effects summary

\begin{tabular}{|c|c|c|c|}
\hline Variable & Liraglutide dose & Side effect & Other consideration \\
\hline Cancer & $0.1-1.8 \mathrm{mg}$ & $\begin{array}{l}\text { Increase when only methodological studies } \\
\text { of high quality were considered. }{ }^{31}\end{array}$ & - \\
\hline Thyroid cancer & $0.1-1.8 \mathrm{mg}$ & No increase $\mathrm{s}^{31}$ & Cases of medullary thyroid carcinoma have been reported during post-approval use. ${ }^{1}$ \\
\hline Pancreatic cancer & 1.2 and $1.8 \mathrm{mg}$ & No increase $e^{32,41,42}$ & $\begin{array}{l}\text { Pancreatic cancer was more commonly reported among patients with T2DM who took } \\
\text { GLP-1 receptor agonists. }{ }^{43}\end{array}$ \\
\hline Breast cancer & 1.8 and $3.0 \mathrm{mg}$ & No increase $e^{44}$ & $\begin{array}{l}\text { Significant increase in breast cancer risk was identified in patients using GLP-1 receptor } \\
\text { agonists for } 2-3 \text { years. }\end{array}$ \\
\hline Prostate cancer & - & $\begin{array}{l}\text { No reports to date relating liraglutide to an } \\
\text { increased risk of prostate cancer }\end{array}$ & - \\
\hline
\end{tabular}

T2DM, type 2 diabetes mellitus; GLP-1, glucagon-like peptide-1. 


\section{Thyroid cancer}

Medullary thyroid tumors have been reported more commonly in rodent toxicology studies using liraglutide compared to human trials, as in the latter, there is a controversy over the relationship between GLP-1 receptor agonists (including 0.6-1.8 mg of liraglutide) and thyroid cancer. ${ }^{46}$

The results of one study indicated no increase in thyroid cancer with the use of liraglutide $(0.1-1.8 \mathrm{mg})$ in patients with T2DM. ${ }^{31}$ Medullary thyroid carcinomas rarely express the GLP-1 receptor in vitro, while papillary thyroid cancers do not express the receptor. ${ }^{47}$ Therefore, only GLP-1 receptor-positive medullary thyroid carcinomas can be candidates for in vivo GLP-1 receptor targeting. Cases of medullary thyroid carcinoma have been reported during postapproval use of liraglutide. ${ }^{1}$

\section{Pancreatic cancer}

According to a claim-based study, there was no increased risk of pancreatic cancer with liraglutide compared to other antidiabetic drugs. ${ }^{32}$ However, pancreatic cancer has been reported more commonly among T2DM patients taking GLP-1 receptor agonists or DPP4 inhibitors compared to other therapies. ${ }^{43}$ Recent studies have suggested that GLP-1 receptor agonists (including 1.2 and $1.8 \mathrm{mg}$ of liraglutide) do not increase the risk for pancreatic cancer when compared to other treatments ${ }^{41}$ or placebo ${ }^{42}$ in T2DM patients.

In a human pancreatic cancer cell study, GLP-1 receptor activation had an antitumor effect on human pancreatic cancer via inhibition of the phosphoinositide 3-kinases/protein kinase B pathway. ${ }^{48}$ As normal ductal epithelial cells, pancreatic intraepithelial neoplasia 3, or ductal pancreatic carcinomas do not express the GLP-1 receptor, it seems that the receptors are not involved in the neoplastic transformation in the pancreas. ${ }^{47}$

\section{Breast cancer}

Liraglutide may have a role in the inhibition of proliferation as well as promotion of apoptosis in human breast cancer cells (MCF-7) by inhibiting microRNA-27a and subsequently increasing the expression of adenosine monophosphate-activated protein kinase catalytic subunit $\alpha 2$ protein. ${ }^{49}$ However, a prospective cohort study suggested that there is no association between liraglu- tide ( 1.8 and $3.0 \mathrm{mg}$ ) use and female breast cancer in a real-world setting. ${ }^{44}$ According to a similar study, as compared with DPP-4 inhibitors, the risk of breast cancer increased in patients treated with GLP-1 receptor agonists for 2-3 years, although the use of GLP-1 receptor agonists did not increase the risk of breast cancer overall. ${ }^{45}$ GLP-1 receptors have been located on human breast tissue, and the interaction between GLP-1 receptor agonists and the fibroblast growth factor 7 /fibroblast growth factor receptor 2 axis could stimulate proliferation of a subset of early breast cancers. ${ }^{45}$

\section{Prostate cancer}

Liraglutide attenuates prostate cancer growth through regulation of the $\mathrm{p} 38$ pathway by binding with the GLP-1 receptor in vitro. ${ }^{50}$ Forced expression of GLP-1 receptor attenuates prostate cancer cell proliferation by inhibiting cell cycle progression in vitro and in vivo. ${ }^{51} \mathrm{~A}$ recent study also showed that an anticancer drug and liraglutide decreased the viability of prostate cancer cells (LNCaP) synergistically. ${ }^{52}$ To date, there are no reports relating liraglutide to an increased risk of prostate cancer.

\section{HEART RATE}

Liraglutide (1.2 and $1.8 \mathrm{mg}$ ) is associated with increased heart rate for patients with T2DM. ${ }^{17,18}$ This increase may be a mechanism of compensation for the hypotensive effect of GLP-1 receptor agonists. It is more likely that the increase in heart rate results from a direct GLP-1 receptor effect on myocytes in the human heart sinoatrial node and/or the sympathetic nervous system stimulation related to inhibition of the autonomic nervous system. ${ }^{53}$

\section{GASTROINTESTINAL SYMPTOMS}

According to a recent study, liraglutide $(0.6-1.8 \mathrm{mg})$ as an adjunct to insulin in patients with T1DM significantly increased gastrointestinal adverse reactions (nausea and vomiting). ${ }^{19}$ Earlier reports found that the most commonly observed adverse reactions associated with liraglutide $(0.6-1.9 \mathrm{mg})$ were gastrointestinal symptoms including nausea, vomiting, dyspepsia, constipation, and diarrhea compared to other therapies or placebo in patients with T2DM. $\cdot^{13,20-23} \mathrm{~A}$ dose of $3.0 \mathrm{mg}$ of liraglutide for the treatment 
of obesity in non-diabetic individuals led to higher incidence of nausea compared to placebo. ${ }^{3}$

\section{HYPOGLYCEMIA}

Various studies have evaluated the use of liraglutide in both T1DM and T2DM patients. The results of one such study suggested that there were no differences in severe hypoglycemia between liraglutide $(0.6-1.8 \mathrm{mg})$ and placebo or any other comparator as adjunct to insulin in patients with T1DM. ${ }^{19}$ Another study of Japanese adults with uncontrolled T2DM, who were prescribed $0.9 \mathrm{mg}$ of liraglutide or DPP-4 inhibitors, found that the treatments were not statistically differentiable with respect to risk of hypoglycemia. ${ }^{24}$

The use of liraglutide $(0.6-1.8 \mathrm{mg})$ in T2DM combined with metformin also did not increase the risk of hypoglycemia. ${ }^{22,25} \mathrm{No}$ excess of hypoglycemia was even observed between GLP-1 receptor agonists and placebo in patients with T2DM with or without established cardiovascular disease. ${ }^{48}$ However, it is recommended that co-administered antidiabetic drugs such as sulfonylurea or insulin be adjusted according to glucose monitoring results and hy- poglycemic risk. $^{1}$

\section{CONCLUSION}

Fig. 1 shows a graphical summary of adverse reactions associated with liraglutide. Liraglutide is associated with an increase in serum lipase and amylase levels. The absolute risk of AP compared to placebo was numerically higher for liraglutide. Liraglutide may also lead to an increased risk of acute gallbladder or biliary disease. Although it does not seem to play an active role in the development of cancer, liraglutide may be associated with an increased risk of thyroid, pancreatic, and early breast cancer considering its post-approval use and the location of GLP-1 receptors.

The most commonly observed adverse reactions associated with liraglutide were gastrointestinal symptoms, and it also may increase the heart rate of T2DM patients. Although liraglutide does not seem to increase the risk of hypoglycemia, it is essential to adjust the doses of co-administered antidiabetic drugs according to glucose monitoring results and the hypoglycemic risk of patients.

There have been several instances of withdrawal or discontinua-

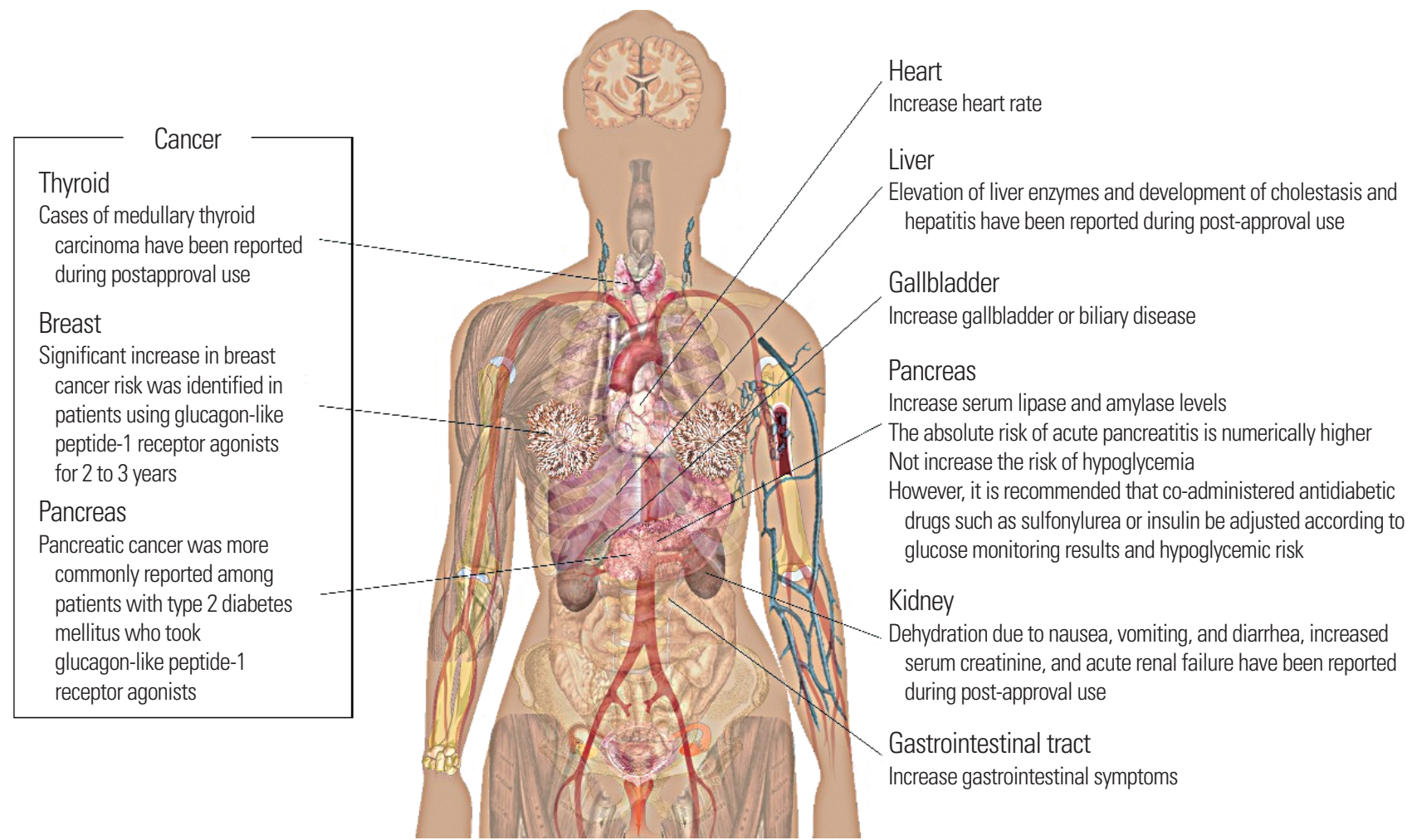

Figure 1. Graphical summary of adverse reactions associated with liraglutide. 
tion of liraglutide prescription due to adverse reactions. Therefore, it is important to exercise precaution and refrain from over-prescribing the drug considering only its efficacy, and to administer liraglutide in accurate doses according to the patient's health condition. Monitoring adverse reactions in patients is equally necessary to minimize any long-term damage to patient health.

\section{CONFLICTS OF INTEREST}

Young-Gyun Seo is the Editorial Board member of the Journal of Obesity \& Metabolic Syndrome. However, he is not involved in the peer reviewer selection, evaluation, or decision process of this article. Otherwise, no other potential conflicts of interest relevant to this article were reported.

\section{REFERENCES}

1. Food and Drug Administration. Prescribing information for Saxenda, 2018 [Internet]. Maryland: Food and Drug Administration; 2018 [cited 2020 May 29]. Available from: https:// www.accessdata.fda.gov/drugsatfda_docs/label/2018/ 206321s007lbl.pdf

2. Khera R, Murad MH, Chandar AK, Dulai PS, Wang Z, Prokop LJ, et al. Association of pharmacological treatments for obesity with weight loss and adverse events: a systematic review and meta-analysis. JAMA 2016;315:2424-34.

3. Zhang P, Liu Y, Ren Y, Bai J, Zhang G, Cui Y. The efficacy and safety of liraglutide in the obese, non-diabetic individuals: a systematic review and meta-analysis. Afr Health Sci 2019;19: 2591-9.

4. Steinberg WM, Buse JB, Ghorbani ML, Ørsted DD, Nauck MA; LEADER Steering Committee, et al. Amylase, lipase, and acute pancreatitis in people with type 2 diabetes treated with liraglutide: results from the LEADER randomized trial. Diabetes Care 2017;40:966-72.

5. Steinberg WM, Rosenstock J, Wadden TA, Donsmark M, Jensen CB, DeVries JH. Impact of liraglutide on amylase, lipase, and acute pancreatitis in participants with overweight/obesity and normoglycemia, prediabetes, or type 2 diabetes: secondary analyses of pooled data from the SCALE Clinical devel- opment program. Diabetes Care 2017;40:839-48.

6. Jensen TM, Saha K, Steinberg WM. Is there a link between liraglutide and pancreatitis? A post hoc review of pooled and patient-level data from completed liraglutide type 2 diabetes clinical trials. Diabetes Care 2015;38:1058-66.

7. Nauck MA, Muus Ghorbani ML, Kreiner E, Saevereid HA, Buse JB; LEADER Publication Committee on behalf of the LEADER Trial Investigators. Effects of liraglutide compared with placebo on events of acute gallbladder or biliary disease in patients with type 2 diabetes at high risk for cardiovascular events in the LEADER randomized trial. Diabetes Care 2019; 42:1912-20.

8. Nreu B, Dicembrini I, Tinti F, Mannucci E, Monami M. Cholelithiasis in patients treated with glucagon-like peptide-1 receptor: an updated meta-analysis of randomized controlled trials. Diabetes Res Clin Pract 2020;161:108087.

9. Armstrong MJ, Houlihan DD, Rowe IA, Clausen WH, Elbrønd B, Gough SC, et al. Safety and efficacy of liraglutide in patients with type 2 diabetes and elevated liver enzymes: individual patient data meta-analysis of the LEAD program. Aliment Pharmacol Ther 2013;37:234-42.

10. Dong Y, Lv Q, Li S, Wu Y, Li L, Li J, et al. Efficacy and safety of glucagon-like peptide-1 receptor agonists in non-alcoholic fatty liver disease: a systematic review and meta-analysis. Clin Res Hepatol Gastroenterol 2017;41:284-95.

11. Famularo G, Gasbarrone L, Minisola G. Pancreatitis during treatment with liraglutide. JOP 2012;13:540-1.

12. Kern E, VanWagner LB, Yang GY, Rinella ME. Liraglutide-induced autoimmune hepatitis. JAMA Intern Med 2014;174: 984-7.

13. Liu W, Yu J, Tian T, Miao J, Shang W. Meta-analysis of the efficacy of liraglutide in patients with type 2 diabetes accompanied by incipient nephropathy. Exp Ther Med 2019;18:34251.

14. Pasternak B, Wintzell V, Eliasson B, Svensson AM, Franzén S, Gudbjörnsdottir S, et al. Use of glucagon-like peptide 1 receptor agonists and risk of serious renal events: scandinavian cohort study. Diabetes Care 2020;43:1326-35.

15. Kaakeh Y, Kanjee S, Boone K, Sutton J. Liraglutide-induced acute kidney injury. Pharmacotherapy 2012;32:e7-11. 
16. Narayana SK, Talab SK, Elrishi MA. Liraglutide-induced acute kidney injury. Pract Diabetes 2012;29:380-2.

17. Zhao D, Liu H, Dong P. Liraglutide reduces systolic blood pressure in patients with type 2 diabetes mellitus: a meta-analysis of randomized trials. Clin Exp Hypertens 2020;42:393400.

18. Robinson LE, Holt TA, Rees K, Randeva HS, O’Hare JP. Effects of exenatide and liraglutide on heart rate, blood pressure and body weight: systematic review and meta-analysis. BMJ Open 2013;3:e001986.

19. Dimitrios P, Michael D, Vasilios K, Konstantinos S, Konstantinos I, Ioanna Z, et al. Liraglutide as adjunct to insulin treatment in patients with type 1 diabetes: a systematic review and meta-analysis. Curr Diabetes Rev 2020;16:313-26.

20. Du Q, Wang YJ, Yang S, Zhao YY, Han P. Liraglutide for the treatment of type 2 diabetes mellitus: a meta-analysis of randomized placebo-controlled trials. Adv Ther 2014;31:1182-95.

21. Li M, Yang Y, Jiang D, Ying M, Wang Y, Zhao R. Efficacy and safety of liraglutide versus sitagliptin both in combination with metformin in patients with type 2 diabetes: a systematic review and meta-analysis. Medicine (Baltimore) 2017;96:e8161.

22. Gu J, Meng X, Guo Y, Wang L, Zheng H, Liu Y, et al. The efficacy and safety of liraglutide added to metformin in patients with diabetes: a meta-analysis of randomized controlled trials. Sci Rep 2016;6:32714.

23. Shomali ME, Ørsted DD, Cannon AJ. Efficacy and safety of liraglutide, a once-daily human glucagon-like peptide-1 receptor agonist, in African-American people with type 2 diabetes: a meta-analysis of sub-population data from seven phase III trials. Diabet Med 2017;34:197-203.

24. Ayers D, Kanters S, Goldgrub R, Hughes M, Kato R, Kragh N. Network meta-analysis of liraglutide versus dipeptidyl peptidase- 4 inhibitors for the treatment of type 2 diabetes in Japanese patients. Curr Med Res Opin 2017;33:1653-61.

25. Lorenzi M, Ploug UJ, Langer J, Skovgaard R, Zoratti M, Jansen J. Liraglutide versus SGLT-2 inhibitors in people with type 2 diabetes: a network meta-analysis. Diabetes Ther 2017;8: 85-99.

26. Singh S, Chang HY, Richards TM, Weiner JP, Clark JM, Segal JB. Glucagonlike peptide 1-based therapies and risk of hospi- talization for acute pancreatitis in type 2 diabetes mellitus: a population-based matched case-control study. JAMA Intern Med 2013;173:534-9.

27. Lando HM, Alattar M, Dua AP. Elevated amylase and lipase levels in patients using glucagonlike peptide-1 receptor agonists or dipeptidyl-peptidase-4 inhibitors in the outpatient setting. Endocr Pract 2012;18:472-7.

28. Meier JJ, Nauck MA. Risk of pancreatitis in patients treated with incretin-based therapies. Diabetologia 2014;57:1320-4.

29. Buse JB, Bethel MA, Green JB, Stevens SR, Lokhnygina Y, Aschner P, et al. Pancreatic safety of sitagliptin in the TECOS study. Diabetes Care 2017;40:164-70.

30. Abbas AS, Dehbi HM, Ray KK. Cardiovascular and non-cardiovascular safety of dipeptidyl peptidase- 4 inhibition: a meta-analysis of randomized controlled cardiovascular outcome trials. Diabetes Obes Metab 2016;18:295-9.

31. Alves C, Batel-Marques F, Macedo AF. A meta-analysis of serious adverse events reported with exenatide and liraglutide: acute pancreatitis and cancer. Diabetes Res Clin Pract 2012; 98:271-84.

32. Funch D, Gydesen H, Tornøe K, Major-Pedersen A, Chan KA. A prospective, claims-based assessment of the risk of pancreatitis and pancreatic cancer with liraglutide compared to other antidiabetic drugs. Diabetes Obes Metab 2014;16:273-5.

33. Rehfeld JF, Knop FK, Asmar A, Madsbad S, Holst JJ, Asmar M. Cholecystokinin secretion is suppressed by glucagon-like peptide-1: clue to the mechanism of the adverse gallbladder events of GLP-1-derived drugs. Scand J Gastroenterol 2018; 53:1429-32.

34. Luo Y, Yang P, Li Z, Luo Y, Shen J, Li R, et al. Liraglutide improves non-alcoholic fatty liver disease in diabetic mice by modulating inflammatory signaling pathways. Drug Des Devel Ther 2019; 13:4065-74.

35. Han X, Ding C, Zhang G, Pan R, Liu Y, Huang N, et al. Liraglutide ameliorates obesity-related nonalcoholic fatty liver disease by regulating Sestrin2-mediated $\mathrm{Nrf} 2 / \mathrm{HO}-1$ pathway. Biochem Biophys Res Commun 2020;525:895-901.

36. Yang M, Ma X, Xuan X, Deng H, Chen Q, Yuan L. Liraglutide attenuates non-alcoholic fatty liver disease in mice by regulating the local renin-angiotensin system. Front Pharmacol 2020; 
$11: 432$.

37. Zhang N, Tao J, Gao L, Bi Y, Li P, Wang H, et al. Liraglutide attenuates nonalcoholic fatty liver disease by modulating gut microbiota in rats administered a high-fat diet. Biomed Res Int 2020;2020:2947549.

38. Su K, Yi B, Yao BQ Xia T, Yang YF, Zhang ZH, et al. Liraglutide attenuates renal tubular ectopic lipid deposition in rats with diabetic nephropathy by inhibiting lipid synthesis and promoting lipolysis. Pharmacol Res 2020;156:104778.

39. Hviid AV, Sørensen CM. Glucagon-like peptide-1 receptors in the kidney: impact on renal autoregulation. Am J Physiol Renal Physiol 2020;318:F443-54.

40. Liu Y, Zhang X, Chai S, Zhao X, Ji L. Risk of malignant neoplasia with glucagon-like peptide-1 receptor agonist treatment in patients with type 2 diabetes: a meta-analysis. J Diabetes Res 2019;2019:1534365.

41. Pinto LC, Falcetta MR, Rados DV, Leitão CB, Gross JL. Glucagon-like peptide-1 receptor agonists and pancreatic cancer: a meta-analysis with trial sequential analysis. Sci Rep 2019;9: 2375.

42. Marsico F, Paolillo S, Gargiulo P, Bruzzese D, Dell'Aversana S, Esposito I, et al. Effects of glucagon-like peptide-1 receptor agonists on major cardiovascular events in patients with type 2 diabetes mellitus with or without established cardiovascular disease: a meta-analysis of randomized controlled trials. Eur Heart J 2020;41:3346-58.

43. Elashoff M, Matveyenko AV, Gier B, Elashoff R, Butler PC. Pancreatitis, pancreatic, and thyroid cancer with glucagon-like peptide-1-based therapies. Gastroenterology 2011;141:150-6.

44. Funch D, Mortimer K, Li L, Norman H, Major-Pedersen A, Olsen $\mathrm{AH}$, et al. Is there an association between liraglutide use and female breast cancer in a real-world setting? Diabetes Metab Syndr Obes 2018;11:791-806.

45. Hicks BM, Yin H, Yu OH, Pollak MN, Platt RW, Azoulay L.
Glucagon-like peptide- 1 analogues and risk of breast cancer in women with type 2 diabetes: population based cohort study using the UK Clinical Practice Research Datalink. BMJ 2016; 355:i5340.

46. Gallo M. Thyroid safety in patients treated with liraglutide. J Endocrinol Invest 2013;36:140-5.

47. Waser B, Blank A, Karamitopoulou E, Perren A, Reubi JC. Glucagon-like-peptide-1 receptor expression in normal and diseased human thyroid and pancreas. Mod Pathol 2015;28: 391-402.

48. Zhao H, Wang L, Wei R, Xiu D, Tao M, Ke J, et al. Activation of glucagon-like peptide-1 receptor inhibits tumourigenicity and metastasis of human pancreatic cancer cells via PI3K/Akt pathway. Diabetes Obes Metab 2014;16:850-60.

49. Zhao W, Zhang X, Zhou Z, Sun B, Gu W, Liu J, et al. Liraglutide inhibits the proliferation and promotes the apoptosis of MCF-7 human breast cancer cells through downregulation of microRNA-27a expression. Mol Med Rep 2018;17:5202-12.

50. Li XN, Bu HM, Ma XH, Lu S, Zhao S, Cui YL, et al. Glucagon-like peptide-1 analogues inhibit proliferation and increase apoptosis of human prostate cancer cells in vitro. Exp Clin Endocrinol Diabetes 2017;125:91-7.

51. Shigeoka T, Nomiyama T, Kawanami T, Hamaguchi Y, Horikawa T, Tanaka T, et al. Activation of overexpressed glucagonlike peptide-1 receptor attenuates prostate cancer growth by inhibiting cell cycle progression. J Diabetes Investig 2020;11: 1137-49.

52. Eftekhari S, Montazeri H, Tarighi P. Synergistic anti-tumor effects of liraglutide, a glucagon-like peptide-1 receptor agonist, along with Docetaxel on LNCaP prostate cancer cell line. Eur J Pharmacol 2020;878:173102.

53. Lorenz M, Lawson F, Owens D, Raccah D, Roy-Duval C, Lehmann A, et al. Differential effects of glucagon-like peptide-1 receptor agonists on heart rate. Cardiovasc Diabetol 2017;16:6. 